\title{
Los tabúes de la menarquia: Un acercamiento a la vivencia de jóvenes escolares chilenas
}

\author{
The taboos of menarche: An approach to the experience \\ of young chilean students
}

Daniela Fernández Olguin ${ }^{1}$

\section{Resumen}

La menarquia, si bien se describe como relevante dentro de la subjetividad de las mujeres, no ha tenido la suficiente relevancia dentro de las investigaciones y desarrollos del tema en la actualidad. Esta investigación busca describir y analizar el funcionamiento de los tabúes que operan en la vivencia de la menarquia de una selección de casos de jóvenes chilenas, dentro de un intervalo cercano y posterior a su ocurrencia. Se utiliza la metodología cualitativa del análisis de casos y como instrumento de recopilación de información la entrevista semiestructurada. A partir de lo investigado, se expone que el tabú opera en distintas dimensiones para las jóvenes: la familia, su cuerpo y los vínculos construidos con el otro diferente.

Palabras clave: tabú, menarquia, adolescencia, género, sexualidad.

\begin{abstract}
Even though menarche has been described as relevant to women's subjectivity, it hasn't had enough relevance among research and developments in the subject currently. This research attempts to describe and analyze the processes under which taboos work in the ex-
\end{abstract}

1 Docente de la Escuela de Psicología y Trabajo Social de la Universidad Viña del Mar. Valparaíso, Chile. E-mail: daniela.paz.f@gmail.com 
perience of menarche in a selection of young chilean females, within a time frame prior and posterior to their menarche. A qualitative methodology of case analysis is used, and the information is gathered with a semistructured interview. It is exposed that the taboos work in different dimensions for young women: family, their body and the bonds built with different others.

Key words: taboo, menarche, adolescence, gender, sexuality.

Me contaron las tías viejas que el kutrán killén les pasó a las mujeres porque una noche que había luna llena -quizás cuándo sería, en qué año sería eso- una niña salió a mear afuera de la ruka, ella no se dio cuenta que le mostró su kutre a la luna. La luna le pegó una mirada tan fuerte que la castigó, por eso le salió sangre.

(Montecino, 1999, p. 56)

Planteamiento del problema y perspectiva teórica

La menarquia es considerada uno de los eventos centrales dentro de la vida sexual femenina, simbolizando en diferentes culturas el abandono de la infancia y la transición del estado de niña al de mujer. Esto, debido a la adquisición por parte de la joven de la capacidad de maternidad, lo cual implica una nueva comprensión de su cuerpo y sexualidad (Beauvoir, 1999; Dio Bleichmar, 2002; Dolto, 1982). Se llama menarquia al primer sangramiento y período menstrual que acaece en la vida de una nińa, ocasionando el inicio de la menstruación, la cual se mantendrá durante su vida fértil. La edad promedio considerada para la menarquia en Chile es de 12,6 años (Hernández, Unanue, Gaete, Cassorla \& Codner, 2007), lo que expone la tendencia secular que ha sido descrita actualmente para este evento.

La importancia que adquiere la menarquia para la vida de las jóvenes ha llevado a que sea relacionada con diferentes interpretaciones culturales y sociales para poder sobrellevar y comprender su vivencia, una de las cuales corresponde a los tabúes. Los tabúes son definidos como diferentes prohibiciones que operan en diversos aspectos de la vida social, 
significando y normando la subjetividad de los miembros del colectivo (Freud, 1991). El tabú no solo funciona como prohibición o veto, sino que, a su vez, produce discursos como consecuencia de estas prohibiciones: no es solo lo que no se puede decir o hacer, sino qué se puede y cómo está permitido decirse o realizarse. Para Foucault (2002), el tabú -como mecanismo de orden y control social- opera intentando regular temáticas prohibidas, que pasan a ser normadas y controladas a partir de maneras aceptadas y validadas de vivenciarlas, decirlas y hacerlas públicas, más que de ocultarlas. De esta forma, el tabú no solo restringe, sino que construye y reproduce significados y prácticas que adquieren sentido dentro del nudo colectivo en el cual funcionan.

Tabú y menarquia han sido relacionados histórica y culturalmente de variadas maneras, según el contexto sociohistórico en donde opere esta relación. Dentro del contexto chileno, por ejemplo, González y Montero (2008) exponen que si bien hoy se tiene acceso a mayores fuentes de información dentro de la escuela y la familia, esta información se centra en aspectos higiénicos de carácter inmediato y biológicos obvios, siendo excluida la experiencia de la propia joven con su cuerpo y su emocionalidad. Así, la comprensión subjetiva y explicación del evento es omitida, y se da preferencia a otro tipo de información que viene a perpetuar mitos y tabúes en las jóvenes, justificados en la ignorancia que poseen respecto al tema (Sotomayor, García, Butte \& Cid, 2003). A este respecto, considerando la transmisión de información sobre sexualidad en los medios de comunicación y ámbito escolar, se podría asumir una disminución en la sensación de sorpresa que solía tener la menarquia y, a partir de esto, establecer que no sería vivida como un tema tabú para las jóvenes. Sin embargo, el estudio de González y Montero (2008), señala que a pesar de recibir información previa, la ignorancia, extrañeza y el temor en la llegada de la menarquia se mantiene, debido a la carencia y precariedad de información, lo cual profundiza la construcción y transmisión de tabúes sobre este evento y sus implicancias. Según este estudio, dentro de las principales fuentes de información sobre la menstruación está primero la madre, luego la escuela y finalmente hermanas o amigas. 
A partir de esto surgen diferentes preguntas en relación al por qué, a pesar de los avances socioculturales y educacionales que se plantean en torno a la enseñanza sobre la sexualidad y apertura del tema, la menarquia mantiene un carácter de sorpresa y extrañeza por parte de las jóvenes. Pareciera ser que el tabú continúa relacionándose con la vivencia de la menarquia, variando sus prohibiciones y significados construidos en relación al tema. Por otro lado, los acercamientos teóricos más contemporáneos que se han realizado para el estudio de la menarquia se han enfocado o bien dentro del trabajo cuantitativo con la recopilación de información a partir de cuestionarios y encuestas, o bajo la predominancia de un enfoque biológico para comprender las consecuencias de la menarquia en las jóvenes (Burin \& Meler, 1998; González \& Montero, 2008; Montenegro, 2000).

A raíz de esto, se hace necesario abordar el estudio de la menarquia comprendiendo los diferentes procesos anímicos e intersubjetivos que tienen lugar durante la pubertad y adolescencia, reconociendo el carácter dinámico de estas etapas y su funcionamiento como un devenir personal e histórico (Bilbao \& Morlans, 2009). Se torna pertinente lograr acercarnos a la realidad actual y contextualizada de este evento, indagando cómo funcionan hoy los tabúes que operan en la experiencia de la menarquia de las jóvenes, a partir de sus propios testimonios y significados personales construidos en torno al evento. De este modo, el objetivo de la investigación consistió en describir y analizar el funcionamiento de los tabúes que operan en la vivencia de la menarquia de jóvenes escolares chilenas, pertenecientes a la comuna de Valparaíso, en un intervalo próximo y posterior a su ocurrencia.

El funcionamiento del tabú se comprende como un proceso dinámico y relacional bajo el cual -mediante sus diferentes interdiccionestambién se incorporan representaciones simbólicas y significados socioculturales. A partir de este objetivo se busca indagar sobre las condiciones sociohistóricas en las cuales se produce la menarquia y sus implicancias en la subjetividad de las jóvenes, considerando los contextos personales en los cuales esta transformación acaece. De este modo, el tabú permite reflexionar sobre el anudamiento de las relaciones de poder y significados creados 
colectivamente en el cuerpo erógeno, lugar donde se inscriben regulaciones simbólicas e históricas vigentes (Meler, 1997).

En función de esto, se recurrió al psicoanálisis intersubjetivo como perspectiva teórica de trabajo, el cual busca la integración de la importancia que el psicoanálisis clásico asigna a la psicosexualidad y al inconsciente en la construcción del psiquismo, y el reconocimiento de la importancia de las condiciones intersubjetivas y sociohistóricas en el advenimiento de la subjetividad sexuada singular (Meler, 2007). Esta línea teórica se distancia de la postura psicoanalítica clásica, teniendo en mayor consideración la importancia del aspecto vincular en la subjetividad y no exclusivamente el intrapsíquico (Benjamin, 2006; Lyons-Ruth, 1999); y, a su vez, integrando conceptos que se han mantenido alejados del psicoanálisis clásico, como el género -definido como las significaciones construidas en torno al ser varón y ser mujer en las diferentes culturas y subjetividades (Burin \& Meler, 1998) - y su relevancia en la construcción de la subjetividad sexuada. El género no se relaciona solo con procesos de socialización, sino que incluye procesos de significación personal, sentimientos, representaciones y fantasías inconscientes que dan forma, construyen y representan de manera individual al género, por lo que hay múltiples masculinidades o feminidades (Chodorow, 2011).

\section{Metodología}

La estrategia de investigación utilizada fue el estudio de casos basado en metodología cualitativa, centrándose en la profundización de una situación determinada, siendo la información abordada de manera descriptiva e interpretativa.

\section{Definición de muestra}

El estudio se efectuó con base en una selección muestral de cinco estudiantes chilenas que cursaban séptimo básico en una escuela municipal segregada por sexo, de la provincia de Valparaíso. La elección del lugar res- 
ponde a criterios prácticos debido al acercamiento inicial con la profesora jefe del curso, mediante su participación en una organización comunitaria con enfoque de género. Se recurrió a un muestreo intencional de caso típico cuyos criterios fueron: la presentación de su menarquia dentro del año recién transcurrido en el momento de las entrevistas (el cual corresponde al año 2010), todas las jóvenes tenían entre 12 y 13 años, interés voluntario de participación en la investigación y consentimiento firmado del apoderado para participar en las entrevistas.

De este modo, se desarrolló la selección de las participantes: Alejandra (hija única de 13 años, siendo la mayor dentro la muestra), Gabriela (de 12 ańos y quien había presentado la menarquia más precoz dentro de la muestra, a los 11 ańos), Danitza (de 12 años y participante activa de la iglesia evangélica), Loreto (de 12 años y la última de la muestra que había presentado su menarquia) y Claudia (de 12 años, quien refirió temor durante su menarquia ya que se encontraba en la escuela cuando ocurrió, a diferencia del resto de las jóvenes que estaban en su hogar o con algún pariente) $)^{2}$. Todas las participantes, además de cumplir con los criterios expuestos anteriormente, asistían a clases de manera permanente y vivían con uno o ambos padres.

Las jóvenes entrevistadas pertenecían a una escuela segregada por sexo (o no mixta) de la comuna de Valparaíso. Este establecimiento albergaba alumnas desde prekinder a octavo básico, quienes -dentro de los análisis situacionales y visión del profesorado- pertenecían a un contexto familiar y socioeconómicamente vulnerable. Según Sánchez (2003), las jóvenes que se desenvuelven en escuelas segregadas por sexo femenino se muestran más abiertas sobre el tema de la menarquia, vivenciando esta experiencia con menos vergüenza y más orgullo que las jóvenes que asisten a escuelas mixtas. La realización de la investigación en un establecimiento de este tipo entrega elementos más específicos y contextualizados para comprender el evento de la menarquia en la vida de las jóvenes. Según datos del Mineduc (2007), solo un 7\% de los estudiantes a nivel nacional asisten a escuelas diferenciadas por sexo, siendo mayor el proceso de ampliación hacia la educación mixta (Silva-Peña, 2010).

2 Los nombres utilizados son ficticios para mantener la confidencialidad de las entrevistadas. 


\section{Técnicas de recolección de la información}

La técnica de recolección utilizada fue la entrevista en profundidad semiestructurada, la cual permitió una aproximación gradual al testimonio de las entrevistadas. Se realizaron de dos a tres entrevistas, de una duración de 40 minutos en promedio, de acuerdo al principio de saturación de los datos.

Las entrevistas fueron realizadas en dos salas disponibles del establecimiento educacional, durante el horario de clases a cargo de la profesora colaboradora. En las entrevistas se establecieron temas generales, sin restringir los contenidos emergentes que las mismas jóvenes introdujeran, ya que a partir de la reconstrucción del discurso de las jóvenes podían emerger elementos sobre su menarquia que posteriormente fuesen comprendidos a modo de aprés-coup. También se tomó atención a otros elementos de tipo no verbales, como el silencio y el lenguaje corporal, los cuales fueron consignados durante las entrevistas e incluidos en los registros y análisis.

Las entrevistas fueron grabadas con el consentimiento de las jóvenes y posteriormente transcritas de forma íntegra, correspondiendo la unidad de análisis del estudio al funcionamiento del tabú o tabúes que operan en la experiencia de la menarquia de las jóvenes.

\section{Procedimiento de análisis de datos}

Para la realización del análisis de la información se recurrió al análisis de contenido cualitativo, técnica que se presenta como adecuada para indagar los significados presentes en los testimonios de las jóvenes. La categorización fue realizada a partir de la codificación abierta con la totalidad del material, agrupando y clasificando la información que compartiera características similares para ser analizada. La agrupación de los contenidos por analogía consideró el contenido explícito y latente.

Las categorías resultantes del proceso de codificación general fueron utilizadas para describir cada caso con el fin de rescatar los elementos singulares del relato de cada joven. Posteriormente estas fueron analizadas de manera transversal y general en busca de la integración de las 
regularidades y diferencias de los testimonios expuestos por las jóvenes. Las inferencias realizadas fueron justificadas a partir de los elementos teóricos recopilados, ayudando a situar la información en un contexto determinado.

\section{Resultados}

A partir del proceso de codificación realizado de manera emergente con el material extraído de la totalidad de las entrevistas, se formularon las siguientes categorías: La transmisión familiar del tabú; El tabú como búsqueda de significar la menarquia y el cuerpo femenino; y El tabú como forma de exclusión: entre lo público y lo privado.

\section{La transmisión familiar del tabú}

Esta categoría agrupa los contenidos que dan cuenta de la importancia otorgada por las jóvenes a la familia, la diferente relación mantenida con cada uno de sus miembros en el momento de su menarquia, y la reflexión en torno a la participación de ellos en esta vivencia, a través de lo cual se transmiten tabúes en torno a lo prohibido o permitido de realizar durante la menarquia y se instituye un tabú en relación a la elección de a quién se le puede confiar este tema. Como plantean González y Montero (2008), es dentro de la familia -y sobre todo con la figura de la madre- en donde las jóvenes reciben la mayor información sobre el tema, sintiendo confianza y apoyo. La historia y vínculos construidos, que las jóvenes refirieron y valoraron positivamente, favorecieron la transmisión intergeneracional y transgeneracional de tabúes, así como la reflexión y apropiación de estos por parte de las jóvenes.

La madre representa para las jóvenes la figura con quien sienten mayor cercanía e identificación, ya que manifiestan que -al vivenciar los mismos procesos de la menarquia y menstruación- es la que mejor las puede entender. De esta forma, la madre transmite interdicciones familiares y sociales sobre cómo las jóvenes deben vivenciar este evento, las cuales se focalizan en la transmisión de diferentes ideales de género, que toman 
sentido con base en la llegada de la menarquia bajo el rótulo del "ser una señorita”: "igual me dijo que tenía que ser más responsable, limpia y todo eso... preocuparme de andar bien "(Gabriela), o "le dije a mi mamá y me dijo que me felicitaba porque ya había... era señorita, dijo"(Alejandra).

Esta transmisión de tabúes no es neutral ya que, a partir de las reacciones que la madre tiene en el momento de ser informada de la menarquia de su hija, se dejan entrever diferentes emocionalidades a partir de este cambio: "le cambió la cara (...) así como preocupada (...) (silencio) y así como que yo soy la regalona así, pensaba que me estaba perdiendo” (Claudia). La madre, al elegir qué prohibiciones referir a su hija, expresa también de modo consciente o inconsciente la manera en que ella realiza este duelo por la pérdida del sentimiento de poder sobre el cuerpo de su hija, quien ahora vivencia sus propios procesos de forma independiente. En el caso de Alejandra, esta pérdida también da paso a un proceso reflexivo por parte de la madre de sus propios procesos femeninos y los propios tabúes que vivencia con ellos, como en el caso de la menopausia: "(me dice) que uno después se acostumbra (ríe), que después se va a sentir raro, rara sin la menstruación después...”.

El padre, por su parte, se muestra como una figura ausente y poco partícipe, y con base en estas observaciones las jóvenes comienzan a construir un tabú relacionado a no referirse o mencionar este tema a los hombres, ya que a partir de las reacciones (o falta de estas) de su padre, hipotetizan que es un tema que a los hombres no les interesa, bajo la explicación de que al no vivir este proceso no pueden entenderlo. De este modo, se marca inmediatamente la diferencia con la figura materna, que sí vivencia este cambio y lo comprende de mejor manera, como refiere Claudia: "porque me daría vergüenza (ríe) (...) porque él es hombre y no le ha pasado". En el caso de Loreto -a diferencia del resto- el padre sí había manifestado una celebración en torno a la llegada de la menarquia en una de sus visitas, ya que sus padres no convivían, pero Loreto "olvidó" este hecho, recién manifestándolo cuando se le preguntó explícitamente la participación paterna en la menarquia, lo cual puede expresar de manera inconsciente la transmisión del lugar que le es otorgado al padre en la familia 
y en su participación en estos procesos. Loreto, al mismo tiempo, manifestó la preferencia a la madre, esperando a que llegara del trabajo para comunicar por primera vez esta noticia. Esto difiere a lo planteado por Danitza, la cual señaló no tener resistencias a que su padre o su hermano supieran sobre su menarquia, debido a que la madre desde el primer momento le dijo que no era un tema de vergüenza.

Dentro de las narraciones de las jóvenes, la familia se expone como el espacio de confianza al cual han pertenecido durante su infancia. Pero la familia es representada solo por las figuras femeninas que sienten como más próximas, lo que incluye a tías, primas y hermanas mayores $y$, en algunos casos, abuelas. Dentro de los casos, solo Loreto no convivía cotidianamente con estas figuras, lo cual puede relacionarse con la mayor resistencia y sentimientos de soledad que manifestaba debido a la llegada de su menarquia. El reconocimiento que estos miembros femeninos hagan de la menarquia y de sus consecuencias positivas es valorado entre las jóvenes, ya que las hace sentir más cerca de este crecimiento y adultez esperada por la menarquia, construyendo expectativas respecto al cambio y un sentimiento de pertenencia y comunidad con ellas: "que ya no te tratan como la nińa de antes, que no podís hacer nada, y todo eso, pero ahora te tratan como más grande" (Danitza). Esto también implica tener que cumplir ciertas responsabilidades dentro de su familia, las cuales aceptan de forma positiva, ya que fomentan el sentimiento de abandonar su estado de niñas o infantil, sintiéndose responsables y más independientes dentro de su círculo familiar. A pesar de esto, las jóvenes en su mayoría, al reflexionar sobre el tema, describen que su situación y posición dentro de la familia, en la práctica, no ha variado mucho.

\section{El tabú como búsqueda de significar la menarquia y el cuerpo femenino}

La menarquia es vivenciada por las jóvenes como una irrupción y quiebre en su imagen corporal y -si bien forma parte de un proceso de cambios puberales- no se vivencia como un proceso, sino más bien pareciese ocurrir de un momento a otro. Solo a partir de una reflexión posterior 
se advierte cómo el cuerpo fue anunciando y preparando este cambio, mediante transformaciones corporales como el crecimiento de los pechos, una mayor altura o la aparición de vellos en su cuerpo: "bien, pero así fue como todo como muy rápido (...) sí... como que me empezó a salir todo, me dio cosa, porque no sabía que... qué me estaba pasando (...). Igual así me dio... o sea fue fuerte (...)" (Claudia). Dentro de este desplazamiento temporal entre los primeros cambios y la menarquia, algunas jóvenes construyeron fantasías y mitos relacionados con explicaciones para la sangre menstrual: "que era como algo asqueroso al salir sangre, y pensaba que era como una herida que se hacía dentro" (Alejandra), o "como que iba a hacer así, en vez de pipi íbamos, que íbamos a hacer sangre" (Claudia). Las jóvenes que explicitaban este tipo de fantasías no relataban e incluso desestimaban mitos sobre el tema; mientras que las jóvenes que sí refirieron ciertos mitos, no manifestaron fantasías respecto a la menarquia y menstruación, como Gabriela y Loreto que referían mitos transmitidos por sus madres acerca de la relación de la menstruación con cambios de temperatura (como el supuesto peligro de bañarse con agua fría durante estos días).

De esta forma -si bien existe una transmisión de información "oficial" respecto a la menarquia y sus cambios- persisten elementos inconscientes para explicar este evento, como si las explicaciones oficiales no dieran abasto para comprender en su totalidad este cambio corporal y subjetivo de las jóvenes. Esto se manifiesta sobre todo en el aumento de lenguaje corporal y no verbal cuando se hacían referencia a estas temáticas sobre el cuerpo: guardando silencio, moviendo sus pies o tocando partes de su cuerpo en vez de nombrarlas, como en el caso de los ovarios: “(...) a veces me molesta por los dolores (silencio) de acá (se toca con las manos la zona de los ovarios)" (Claudia). En los momentos que no se logra representar el cuerpo puberal en transformación con la palabra, se le utiliza como recurso para decir lo que no logra ser dicho ni significado al otro.

El tabú emerge para las jóvenes en tanto este cuerpo erógeno y sexualizado hace imperativo lograr significar y representar estas transformaciones, así como construir modos de sobrellevarlas en su vida diaria. En el cuerpo toman lugar diferentes explicaciones, tabúes y limitaciones 
-transmitidas por parte de la madre, de la escuela o bien construidas por la propia joven- para significar esta irrupción y lograr sentir que puede mantenerse en control, ya que no debe exponerse en el ojo público la llegada de la menarquia ni ningún rastro de ella. Así, los tabúes al referirse a la menarquia y a las diferentes acciones que puedan exponer este hecho, se comprenden como maneras de borrar las huellas de la irrupción de lo corporal y la extrañeza a partir de esta.

De esta forma, el tabú se erige como un intento de solucionar la tensión que emerge durante la adolescencia sobre la construcción de la intimidad del cuerpo versus la consciencia de vivenciar un cuerpo que es sancionado por la mirada del otro; y para sobrellevar esta tensión se aprehenden diferentes normas que instituyen tabúes. Estas se enmarcan dentro de una visión negativa y peligrosa de la menarquia, vinculada de manera inmediata a precauciones sobre el embarazo: "no sé, que podía estar propensa a embarazarme y todo eso po, que tenía que cuidarme más... cuidarme más de los cabros" (Claudia); como también a las enfermedades de transmisión sexual, y la preocupación por los criterios de normalidad y anormalidad respecto a la vivencia, lo cual se transmite fundamentalmente a partir de la educación formal en la escuela: "(la profesora) más nos habla de las infecciones, de esas cosas, del SIDA, cuando una está expuesta a riesgo... cosas asî" (Loreto). El tema del embarazo se expone como preocupante solo para Loreto, Claudia y Gabriela -quienes recibieron estos mensajes de cuidado de sus madres-; mientras que para Alejandra - quien refirió no haber recibido información sobre este tema- no existiría relación entre menarquia y embarazo. Para Danitza sí existe una relación, pero no es un tema que le preocupe, lo que se contradice con el nerviosismo que manifiesta al tratar este tema: "pero uno ya sabe que si puede tener hijos ahora, no tiene que hacer más... nada... pero... que uno (ríe)... ay se me olvidó la pregunta”.

\section{El tabú como forma de exclusión: entre lo público y lo privado}

La menarquia es referida por las jóvenes como un tema secreto e íntimo, que implica un cambio en su subjetividad. Las transmisiones 
que la joven recibe sobre la menarquia como paso de la niñez a la adultez, representan para ellas el ingreso al mundo femenino, identificándose con otras mujeres que también han vivenciado este cambio. De este modo, mediante las prohibiciones se transmiten ideales de género: "sí, porque también me gusta que los otros me vean que estoy más arreglada, sí... me gusta que me vean bonita" (Alejandra). A partir de esto, las jóvenes se reconocen como diferentes a quienes eran, y al mismo tiempo, similares a otras mujeres: las jóvenes construyen un sentido de sí mismas a partir de la determinación de la igualdad con otras mujeres. Este punto es uno de los que revela mayor agrado por parte de las jóvenes, relatando de forma entusiasta nuevas adquisiciones que sienten les corresponden por su cambio: compras de vestuario, de maquillaje, y actividades como mirar tiendas o salir a pasear con primas mayores.

Por este reconocimiento con el similar, las jóvenes construyen su intimidad con base en confiar en quien vivencie y comprenda estos procesos, siendo catalogado de diferente quien no los tenga, frente al cual son mayores los resguardos a no referirse al tema. Además, las jóvenes observan que la menarquia y menstruación dentro de la esfera social y pública es un tema tabú, que no se habla ni se menciona a pesar de que todos tengan conocimiento de su existencia. Esta observación hace más importante el reconocimiento de la confianza y similitud con el otro para narrar su cambio, así como la exclusión del diferente -mediante el tabú- en las pocas conversaciones sobre el tema: "no mucho... de repente ellas hablan, pero como cambian la conversación, también les da vergüenza parece" (Alejandra). De esta manera, se instituyen limitaciones con el otro, reconocido ahora como diferente, quien se excluye y no tiene derecho a acceder a esta intimidad y resguardo con el que se vive la menarquia.

El otro diferente es para las jóvenes quien no ha vivenciado este proceso, sobre todo la figura masculina, quien en su ignorancia otorga características negativas a este proceso sin comprender la relevancia que tiene para la vida de las jóvenes: "pienso que son ignorantes porque ni saben, hablan sin saber... porque a ellos no les ha pasado eso" (Claudia). De este modo, se comienzan a construir y reconstruir maneras de vincularse, des- 
vincularse y representar al sexo opuesto visto como lejano, representando la diferencia como polaridad y oposición. A partir de esto, se instituye un tabú hacia los hombres debido al desconocimiento y temor a las reacciones desconocidas -y sobre todo negativas- que pueden tener si saben del tema. La falta de convivencia con varones dentro del contexto escolar no propicia sentimientos de colectivo entre ambos sexos y facilita la construcción de temores y juicios de valor ante las reacciones de los hombres, que solo en el caso de Claudia son referidas a figuras concretas: su padre y sus tíos.

Si bien Danitza se alejó de estos comentarios, planteando que a ella no le da vergüenza que los hombres sepan sobre su menarquia, ya que tenía relaciones de amistad con varones dentro de su grupo de amigos de la iglesia, refiere que no ve necesario que ellos sepan sobre este tema, volcándose de igual forma al resguardo como el resto de las entrevistadas: “(...) ellos sirven más para jugar así (ríe), para apoyarte y todo eso pero no son como para contarle las cosas". Al mismo tiempo refiere sobre los hombres: “(...) una cosa es que puedan entender y la otra es que no quieren entender...”.

\section{Discusiones y conclusiones}

La menarquia implica un cambio corporal para las jóvenes, pero de un cuerpo atravesado por tabúes, fantasías, mitos y discursos, según los ordenamientos familiares y sociales bajo los cuales las jóvenes habitan. De igual forma emergen discursos en común sobre cómo las jóvenes vivencian y experimentan un cuerpo diferente, que cambia y hace necesario el recurrir a nuevas formas de convivir con esta transformación y extrañeza que surge.

Según lo narrado por las jóvenes, en el espacio íntimo -expuesto como el núcleo familiar- la menarquia se vive de manera positiva, representando crecimiento y acceso por parte de las jóvenes a emblemas femeninos adultos, como diferente ropa, maquillarse, ver otros programas de televisión, etc. En el espacio público -sobre todo la escuela- la menarquia se vivencia de forma negativa, con resistencias y malestares, buscando que no se haga pública ninguna evidencia de su aparición. Así, la menarquia se experimenta con ambivalencia, bajo la cual se ponen en función diferentes 
tabúes que actúan como modo de búsqueda para otorgar orden y protección frente a este desconocimiento experimentado inicialmente, a modo de doblegar esta extrañeza. Tales tabúes operan en diferentes aspectos y formas de la experiencia de las jóvenes: como un tabú lingüístico a no referirse al tema, hacia acciones que expongan la menarquia y menstruación en lo público, y hacia quien no haya vivenciado la menarquia -sobre todo la figura masculina-, cuyo objetivo sería la exclusión de estas figuras del conocimiento de la menarquia y relación con el proceso. De esta manera, emergen las siguientes discusiones en torno a los resultados expuestos:

\section{El tabú dentro de la familia: la transmisión de un orden social y político}

La familia es el núcleo de mayor importancia para las jóvenes, y dentro de este espacio es donde se transmiten de forma principal diferentes tabúes, siendo la familia circunscrita a sus figuras femeninas como tías, primas o abuelas, donde la madre es la más importante. Así, lo familiar se relaciona de forma inmediata con lo maternal, a pesar de los cambios socioculturales que este rol ha tenido con el paso de los años, como la mayor inserción laboral de las mujeres en Chile que se ejemplifica en cuatro de los casos de la muestra.

El padre se presenta como una figura ausente, y mediante esta poca participación transmite ciertos imaginarios sobre la figura masculina, considerada como lejana y poco empática por la mayor parte de las jóvenes. De esta forma, la madre se mantiene como el soporte afectivo y referente experiencial para este momento, siendo a quien se recurre para preguntas sobre el tema. Esto implica una sobreexigencia para el rol maternal durante este período, ya que en su figura se coloca toda la responsabilidad en torno a la transmisión de información y apoyo durante la menarquia, lo cual no deja de ser complejo considerando que este evento también moviliza afectos y reflexiones para la madre sobre sus procesos femeninos, los cuales influenciarán los decires que transmita y tabúes relacionados.

A partir de lo narrado por las jóvenes, una mayor participación paterna -permitiendo que el padre también se ofrezca como modelo iden- 
tificatorio- podría propiciar una visión más integrativa de estos roles, que transmita desde los primeros vínculos representaciones que apelen a la integración y respeto por las diferencias, más que a una polaridad rígida respecto a los roles de cada miembro. La transmisión de representaciones más integrativas emerge como una tarea importante de promoción desde la infancia y primeros vínculos, ya que dentro de la familia se transmite una estructura política que reproduce una estereotipia y orden de los géneros (Chodorow, 1999), la cual se sustenta en los diferentes tabúes que se refirieron dentro de este grupo. Esta transmisión no apela solo al aprendizaje y socialización, sino también considera lo inconsciente y transgeneracional, lo cual complejiza sus espacios de reflexión y transformación.

El tabú como mecanismo de orden para la experiencia puberal y el encuentro con la sexualidad

La menarquia es descrita por las jóvenes como un quiebre en su imagen y experiencia corporal, bajo lo cual ellas buscan diferentes formas de sentir un control sobre esta irrupción y descontrol que refieren. Con este objetivo instituyen diferentes tabúes, los cuales se refieren mayormente a limitaciones de actos corporales que expongan su menarquia. Como se refiere en los relatos de las entrevistadas, se clasifica y ordena el cuerpo y la sexualidad de las jóvenes adolescentes mediante diferentes normativas como la producción de parámetros de lo que es normal o anormal de vivenciar durante la menarquia, diferentes limitaciones de actividades que no expongan en el juicio público la aparición de la menarquia, mediante el tabú lingüístico y de restricción hacia la vida sexual en general, y la transmisión de métodos de prevención del embarazo y las enfermedades de transmisión sexual.

La menarquia para las jóvenes implica la apropiación y el cumplimiento de diferentes normas y tabúes que regulan su sexualidad, ignorando la emocionalidad y experiencia personal respecto a este evento, como fue descrito por las jóvenes entrevistadas. Empero, tales normas y discursos no parecen ser suficientes, ya que a pesar de que los silencios 
intentan llenarse con discursos que instituyen "saberes oficiales" en busca de representar y significar la crisis de la pubertad y adolescencia con el apoyo del saber científico, hay una emergencia de lo inconsciente (como las fantasías y mitos relatados) que irrumpe y presiona. De este modo, se manifiesta más bien una sobreestimación de la información transmitida por la familia y escuela, la cual no genera impacto ni propicia una experiencia más informada y positiva en las jóvenes.

\section{Lo sagrado y los ritos de la menarquia}

A partir de los discursos de las entrevistadas, es posible interpretar cómo en la menarquia lo sagrado puede ser relacionado con el cuerpo y la sexualidad, representados por la sangre menstrual, en tanto las jóvenes buscan de forma consciente e inconsciente alejar de su conocimiento y mantener en un plano distanciado de su experiencia estos elementos, tal y como lo sagrado buscaba alejarse por medio del tabú, que funcionaba como un modo de protección ante este peligro desconocido (Godelier, 1998).

Con base en esto se ponen en función diferentes ritos para convivir con este peligro. Según lo narrado por las jóvenes, existe poca claridad y orientación frente a la llegada de la menarquia y los cambios que vivencian a partir de esta. De este modo, no se presentan de manera clara pautas sociales en las que las jóvenes se puedan apoyar y así representar este cambio de estado, mostrando una carencia de saber social y cultural frente al evento y sus implicancias, bajo lo cual se ponen en acción tabúes como respuesta ante la poca claridad e inseguridad descrita por ellas. Esta modalidad simbólica no existe dentro de los colectivos a los que las jóvenes pertenecían, lo que facilita que la menarquia sea vivenciada con desorientación y sentimientos de soledad. La falta de reconocimiento y ritos en torno a este cambio, favorece que las jóvenes se sientan y mantengan en un estado "liminal" -como refería Van Gennep (1969)-, asociado con tabúes y dificultades para reconocer y reconocerse en su nuevo estado.

A pesar de esta carencia social se manifiestan actos simbólicos que toman el carácter de ritos (aunque no de forma explícita) y que propician 
que el tabú no sea la forma única con la cual significar y convivir con la menarquia y sus implicancias. Un ejemplo es la participación en la iglesia evangélica de Danitza, bajo la cual se transmite la noción de cambio de etapa a partir de su ingreso a la alabanza como signo de crecimiento. Otro ejemplo es cómo dentro de las narraciones de las jóvenes se describen en la familia formas de ritos como el otorgar regalos en el momento posterior a la menarquia por parte de la madre (solo en el caso de Loreto el padre le otorgó regalos); el reconocimiento verbal por parte de los miembros de sexo femenino y el crecimiento que implica; y la transmisión de nuevas responsabilidades y derechos que las jóvenes adquieren debido a este cambio.

Para las jóvenes no se vive de manera clara el paso de un estado a otro de forma definida, sino que se mantiene un sentimiento de que los cambios son pequeños y no tan significativos como eran esperados. Así, se manifiesta la tendencia a la pérdida de ritos en la actualidad (Bilbao \& Morlans, 2009) y aparece una multiplicidad de significados y representaciones que se cruzan entre los discursos tradicionales y los posmodernos, frente a los cuales las jóvenes entrevistadas más bien presentan confusión y poca identificación. Así, debido a las contradicciones que acarrean las transformaciones socioculturales presentes, la menarquia y sus ritos se mantienen dentro del plano privado.

\section{Tabú y menarquia: orden y exclusión en las relaciones intergenéricas}

A partir de la transmisión de tabúes, se transmiten prohibiciones que reproducen lo que se significa como el ser mujeres o el "ser señorita". Mediante las interdicciones, se constituyen diferentes ideales de género; no solo como una interdicción externa que se recibe desde lo familiar y lo social, sino que también operando psíquicamente en la búsqueda del cumplimiento de los tabúes e ideales que reproducen.

Estos tabúes reglamentan las restricciones y mandatos en la relación que las jóvenes deben tener con su género, valorando de este modo ideales en torno a los emblemas femeninos adultos. Estos ideales van a propiciar 
la construcción de la diferencia a partir de la dicotomía y polaridad para la comprensión de las jóvenes de su género y las relaciones con el sexo opuesto, ya que las atribuciones que las jóvenes realicen para describir y comprender al sexo masculino son marcadas por lo que "no debe hacerse" o lo opuesto a lo considerado femenino. Los tabúes y mandatos continúan siendo excluyentes para cada género, lo cual contribuye a la oposición entre ambos y la falta de reconocimiento: los hombres son representados como "bruscos", "ignorantes", "molestosos"; mientas las mujeres deben ser "bonitas", "educadas", "tranquilas", etc. Así, desde el tabú se facilita y mantiene la separación de los varones y la definición de sí mismas a partir del opuesto.

La falta de integración en el espacio escolar con el sexo opuesto propicia la construcción de imaginarios sobre la figura masculina con base en prejuicios y atribuciones negativas que sustentan un modelo desigual en las relaciones intergenéricas, y reproducen tabúes para la menarquia, lo que difiere con lo planteado por Sánchez (2003). De este modo, el tabú pasa a ser una protección ante el encuentro con la alteridad y la diferencia sexual, puesta en lugar de oposición; por lo que puede inferirse que el contexto de la educación segregada facilita la idea de hombres y mujeres como dos grupos que no poseen un lugar de encuentro ni puntos en común. De esta forma, a partir de lo narrado por las jóvenes, se hace importante abordar la problemática de la menarquia en las jóvenes -y la adolescencia en generalmás allá de su explicación anatómica, temática que se sigue reproduciendo para la vivencia de la sexualidad adolescente.

\section{El tabú a lo desconocido: la falta de espacios de diálogo y reflexión}

Dentro de lo narrado por las jóvenes, es posible interpretar cómo el tabú se instituye en sus diferentes formas frente al temor y resguardo ante lo desconocido: lo que está fuera de la familia de confianza, el cuerpo como extrańo, o bien los hombres como figura diferente. Este temor se ve fomentado por el desconocimiento que las jóvenes vivencian en esta experiencia desde sus grupos cercanos debido a que el tema no se habla, 
lo que ocasiona una sensación de desconfianza bajo la cual la menarquia se vive en soledad y con vergüenza, en vista de la falta de confianza que las jóvenes mantienen con sus grupos de pares, y el temor a la sanción social de hombres y mujeres que no logren empatizar con esta experiencia. Así, se torna relevante la apertura de mayores espacios de diálogo y reflexión que propicien la expresión y escucha del discurso de las jóvenes.

Cobra relevancia el escuchar y reconocer las diferentes historias sobre la menarquia, ya que dentro de los relatos se evidenció que existen diferentes posiciones respecto a este cambio y sus implicancias en la subjetividad de cada joven. La escucha desde sus palabras, sus significados personales y únicos, y la consideración por la cultura familiar y propia de cada joven puede facilitar este reconocimiento, mediante el diálogo y el respeto no solo por las palabras y reflexiones al respecto, sino también por los silencios de las jóvenes; lo cual fue valorado por ellas mismas al finalizar las entrevistas. Es nuestra responsabilidad -como profesionales y participantes de instituciones sociales- el propiciar la escucha a estos procesos de reflexión y transformación subjetiva, así como construir y transmitir representaciones que apelen a la integración y diversidad, para que así el tabú no sea la forma de significar este cambio, sino a través del acercamiento y la construcción por parte de los colectivos de un mecanismo que apoye y escuche estos procesos de subjetivación adolescente, más allá de la transmisión de prejuicios y tabúes desde las instituciones y grupos sociales.

En los relatos, el tabú emerge a partir de la tensión construida por las jóvenes dentro de su discurso entre el ser oídas y expresarse versus el construir espacios de intimidad psíquica, la cual puede doblegarse mediante la facilitación de espacios en los cuales se construyan nuevas maneras de vincularse con este otro diferente, a partir de su reconocimiento y el respeto e integración de su extrañeza en los procesos subjetivos e intersubjetivos de las jóvenes. Se expone como una tarea importante el dar paso a nuevas formas de reconocimiento que apelen a la integración de las diferencias más que a la polaridad rígida, considerando la complejidad del contexto actual posmoderno en el cual las jóvenes se desarrollan (Montecino, 1997). 
Para finalizar se abren nuevas preguntas a partir del acercamiento realizado a las entrevistadas. Si bien se plantea que los tabúes favorecen temores y resistencias en la menarquia, lo cual puede ser disminuido a partir de la búsqueda de mayores espacios de diálogo y reflexión para el grupo adolescente, el tabú no solo funciona a partir de la transmisión consciente, sino que también cobra importancia su carácter transgeneracional. En vista de esto, se abre la pregunta sobre si los intentos de mayor apertura referente a la sexualidad y adolescencia serán suficientes para detener la transmisión e institución de tabúes. Es relevante cuestionar qué posicionamiento se construye -en tanto investigadores, trabajadores de las ciencias sociales y participantes de diferentes colectivos- frente a este deseo de indagar vivencias que forman parte de construcciones culturales y subjetivas, mediante intentos de homogeneizar estas diferentes vivencias bajo un ideal determinado desde otros escenarios, muchas veces ajenos a los mismos sujetos y obviando cómo los tabúes socioculturales son vivenciados a su vez de manera singular.

Los alcances dentro del estudio se relacionan con la facilidad que significó el lograr ingresar a un tipo de establecimiento no mixto para la realización de la investigación, hecho que no ocurrió en escuelas o liceos mixtos con los cuales también se realizaron contactos. ¿Qué tipo de prejuicios o imaginarios se intentan perpetuar si se circunscribe como más "fácil" el hablar estos temas solo entre mujeres? La realización de esta investigación en un establecimiento mixto hubiera significado otro tipo de complejidad, la cual buscaba ser mantenida dentro del tabú por parte de los mismos establecimientos educacionales mixtos (refiriendo, por ejemplo, que se hacía más difícil hacer esta investigación o podía generar conflictos entre los compañeros debido a la presencia masculina en los cursos). Si bien culturalmente se plantean los beneficios de la educación mixta, la permanencia de alumnado en establecimientos de carácter segregado da cuenta del mantenimiento de la idea de invisibilizar la complejidad de la convivencia de los sexos, la cual no logró ser integrada al realizar el estudio en una escuela segregada.

Considerando esto, las preguntas en torno a cómo se vivencia la menarquia y sus tabúes en la complejidad del contexto actual se tornan 
relevantes, y pueden profundizarse en sus diferentes dimensiones y aristas, por ejemplo, ampliando este tipo de investigación en establecimientos mixtos, o indagando en las representaciones que el sexo masculino construye sobre este evento, no solo los pares, sino también dentro de la familia. Estas temáticas presentan nuevos ámbitos de investigación que entregarían nuevos conocimientos que ampliarían las reflexiones sobre esta temática y su relevancia.

\section{Referencias}

Beauvoir, S. (1999). El segundo sexo. Buenos Aires: Sudamericana.

Benjamin, J. (2006). Sujetos iguales, objetos de amor. Buenos Aires: Paidós. Bilbao, A. \& Morlans, I. (2009). Subjetivización, adolescencia, institución: Psicopatología Clínica y Social. Santiago: LOM.

Burin, M. \& Meler, I. (1998). Género y familia. Poder, amor y sexualidad en la construcción de la subjetividad. Buenos Aires: Paidós

Chodorow, N. (1999). The Reproduction of Mothering. California: University of California Press, Ltd.

Chodorow, N. (2011). Individualizing gender and sexuality: Theory and practice. New York: Routledge.

Dio Bleichmar, E. (2002). Anorexia/Bulimia. Un intento de ordenamiento desde el Enfoque Modular-Transformacional. Aperturas Psicoanalíticas: Revista de Psicoanálisis, 4. Recuperado el 22 de diciembre de 2010 de http://es.scribd.com/doc/36950691/Anorexia-y-BulimiaDio-Bleichmar

Dolto, F. (1982). Sexualidad Femenina: la libido genital y su destino femenino. Barcelona: Paidós.

Foucault, M. (2002). Historia de la sexualidad. La voluntad del saber. Buenos Aires: Siglo XXI Editores.

Freud, S. (1991). Tótem y tabú. Tomo XIII. Buenos Aires: Amorrortu.

Godelier, M. (1998). El enigma del don. Barcelona: Paidós.

González, E. \& Montero, A. (2008). Factores psicosociales y culturales que influyen en el evento de la menarquia en adolescentes posmenárquicas. Revista chilena de obstetricia ginecológica, 73(4), 236-243. Recuperado el 4 de febrero de 2010 de http://www.scielo.cl

Hernández, M., Unanue, N., Gaete, X., Cassorla, F. \& Codner, E. (2007). Edad de la menarquia y su relación con el nivel socioeconómico e ín- 
dice de masa corporal. Revista Médica de Chile, 135(11), 1429-1436. Recuperado el 20 de mayo de 2010 de http://www.scielo.cl

Lyons-Ruth, K. (1999). The two-person unconscious: Intersubjective dialogues, enactive relational representation and the emergence of new forms of relational organization. Psychoanalytic Inquiry, 19, 576617. Recuperado el 7 de mayo de 2012 de http://www.pep-web.org Meler, I. (1997). Psicoanálisis y género: Perspectivas teóricas y clínicas. Recuperado el 3 de abril de 2011 de http://www.topia.com.ar

Meler, I. (2007). La querella psicoanalitica por las mujeres: El debate sobre la sexualidad femenina. Recuperado el 17 de mayo de 2010 de http:// www.psiconet.com/foros/genero/querella.htm

Mineduc. (2007). Estadísticas de la educación 2006. Santiago: Mineduc.

Montecino, S. (1997). Palabra dicha. Escritos sobre Género, Identidades, Mestizajes. Universidad de Chile. Facultad de Ciencias Sociales. Serie: Estudios. Recuperado el 2 de mayo de 2011 de http://es.scribd. com/doc/3197472/Sonia-MontecinoLa-Palabra-Dicha

Montecino, S. (1999). Sueño con menguante. Biografía de una machi. Santiago: Editorial Sudamericana.

Montenegro, H. (2000). Educación sexual de niños y adolescentes. Revista médica de Chile, 128(6), 571-573. Recuperado el 2 de mayo de 2011 de http://www.scielo.cl/

Sánchez, M. (2003). Creencias y actitudes sobre la menstruación en mujeres universitarias y no universitarias. Tesis para optar al grado de Licenciado en Psicología y Psicólogo no publicada. Universidad de las Américas Puebla. Recuperado el 11 de octubre de 2010 de http:// catarina.udlap.mx/u_dl_a/tales/navegacion/carrera_lps.html

Silva-Peńa, I. (2010). Repensando la escuela desde la coeducación. Una mirada desde Chile. Revista Venezolana de Estudios de la Mujer, 15(35), 163-176. Recuperado el 2 de mayo de 2011 de http://www. scielo.org.ve

Sotomayor, K., García, A., Butte, K. \& Cid, F. (2003). Pesquisa de alteraciones menstruales en adolescentes. Ponencia presentada en el XLIII Congreso Chileno de Pediatría, Noviembre, Valdivia. Recuperado el 3 de febrero de 2010 de http://www.sochipe.cl/subidos/catalogo5/ congreso-2003.pdf

Van Gennep, A. (1969). Los ritos de paso. Madrid: Alianza Editorial.

Fecha de recepción: 03 de enero de 2012.

Fecha de aceptación: 24 de mayo de 2012. 